\title{
EFEKTIVITAS VIDEO PANDUAN MENGGUNAKAN BAHAN KIMIA UNTUK MENINGKATKAN KESEHATAN DAN KESELAMATAN KERJA DI
} LABORATORIUM

\section{Dewa Putu Subamia1, I Gusti Ayu Nyoman Sri Wahyuni ${ }^{2}$, Ni Nyoman Widiasih³}

1 Jurusan Kimia, Universitas Pendidikan Ganesha, Singaraja, Indonesia

$2 J u r u s a n$ Fisiska dan Pengajaran IPA, Universitas Pendidikan Ganesha, Singaraja, Indonesia

3 Jurusan Biologi dan Perikanan Kelautan, Universitas Pendidikan Ganesha, Singaraja, Indonesia

\author{
A R T I C L E I N F O \\ Article history: \\ Received 28 Oktober 2020 \\ Received in revised form 19 \\ November 2020 \\ Accepted 25 Maret 2021 \\ Available online 25 April \\ 2021
}

Kata Kunci:

Efektivitas

Video Panduan

Kesehatan, Keselamatan

Keywords:

Effectiveness, Video Guide, Health, Safety

\begin{abstract}
A B S T R A K
Masih adanya kecelakaan dalam menggunakan bahan kimia yang berpotensi mengancam kesehatan dan keselamatan praktikan, menunjukkan bahwa pengetahuan kesehatan dan keselamatan kerja di laboratorium kimia masih perlu ditingkatkan. Penelitian ini bertujuan untuk menganalisis efektivitas video panduan menggunakan bahan kimia untuk meningkatkan pengetahuan kesehatan dan keselamatan kerja. Desain penelitian adalah pre-experimental dengan model onegroup pretest-posttest design. Populasi dalam penelitian ini adalah mahasiswa semester 5. Pengambilan sampel dilakukan dengan teknik simple random sampling melalui google form. Jumlah sampel 31 orang dipilih secara acak dari keseluruhan mahasiswa yang mengisi form pre tes dan post tes. Metode pengumpulan data adalah tes dan angket. Analisis data menggunakan uji paired sample $t$ test, dan uji persentase efektivitas. Hasil penelitian menunjukkan nilai rata-rata posttest lebih besar dari nilai rata-rata pretest, mengalami peningkatan yang signifikan. Hasil uji persentase efektivitas $81,50 \%$ terkategori efektif. Berdasarkan
\end{abstract} hasil penelitian tersebut, dapat disimpulkan bahwa pemberian video panduan menggunakan bahan kimia efektif meningkatkan pengetahuan kesehatan dan keselamatan kerja menggunakan bahan kimia.

\begin{abstract}
There are still accidents in using chemicals that have the potential to threaten the health and safety of practitioners, indicating that the knowledge of occupational health and safety in chemical laboratories still needs to be improved. This study aims to analyze the effectiveness of video guidance using chemicals to increase knowledge of occupational health and safety. The research design was preexperimental with a one-group pretest-posttest design. The population in this study were 5th-semester students. Sampling was done by simple random sampling technique via google form. The number of samples 31 people were randomly selected from all students who filled out the pre-test and post-test forms. Data collection methods are tests and questionnaires. Data analysis used paired sample $t$-test, and test the percentage of effectiveness. The results showed that the average posttest score was greater than the pretest average score, which had a significant increase. The result of the percentage test of effectiveness $81.50 \%$ is categorized as effective. Based on the results of this study, it can be concluded that providing video guidance using chemicals is effective in increasing knowledge of occupational health and safety using chemicals.
\end{abstract}

\section{Pendahuluan}

Pemakaian bahan-bahan kimia (berbahaya) pada aktivitas praktikum di laboratorium kimia sulit dihindarkan. Di sisi lain, pemakain bahan-bahan tersebut cepat atau lambat dapat memberi dampak negatif terhadap kesehatan pengguna (praktikan) maupun petugas yang bekerja di laboratorium bahkan berisiko pula bagi lingkungan. Salah satu faktor penyebab kecelakaan kerja di laboratorium kimia adalah paparan bahan kimia (Imansari \& Sunaryantiningsih, 2017; Syakbania \& Wahyuningsih, 2017). Belum maksimalnya penerapan prinsip kesehatan dan keselamatan kerja (K3) pada pratikum juga dapat memicu terjadinya 
kecelakaan (Isnainy et al., 2014; Purnomo \& Saputro, 2016). Memperhatikan begitu besarnya potensi bahaya penggunaan bahan kimia, maka upaya untuk mencegah agar tidak terjadi kecelakaan akibat terpapar bahan kimia sangat urgen untuk dilakukan. Keselamatan dan Kesehatan Kerja (K3) harus diupayakan bagi seluruh bidang kerja maupun pendidikan salah satunya di laboratorium kimia (Goh \& Lee, 2018; Susiani, 2017; Yamin, 2020).

Upaya pencegahan terjadinya kecelakan kerja di laboratorium kimia FMIPA Undiksha sesungguhnya sudah dilakukan. Namun, hasil pengamatan dalam mendampingi kegiatan praktikum sehariharinya di laboratorium kimia organik/biokimia, masih ada praktek-praktek yang berpotensi mengancam kesehatan dan keselamatan praktikan (Subamia et al., 2019). Disebutkan bahwa praktikum kimia oganik dan praktikum biokimia di Laboratorium Kimia FMIPA Undiksha banyak menggunakan pelarut (solvent) yang berbahaya. Hasil observasi di laboratorium menunjukkan, salah satu faktor pemicu kecelakan kerja yang dialami mahasiswa (praktikan) saat bekerja di laboratorium kimia adalah minimnya pengetahuan dan pemahaman mengenai kesehatan dan keselamatan kerja di laboratorium. Hal ini didukung hasil penelitian yang menunjukkan, bahwa 85\% mahasiswa program studi pendidikan kimia tidak tahu cara menggunakan bahan kimia yang aman terhadap kesehatan (Lasia, 2013). Kecelakaan di laboratorium kimia dapat disebabkan kurangnya pengertian atau apresiasi terhadap faktor-faktor fisika-kimia (Isnainy et al., 2014). Kurangnya pengetahuan akan bahaya bahan kimia, sifat dan jenis bahan kimia serta cara menggunakan bahan kimia yang tepat bisa menyebabkan terjadinya kecelakaan kerja (Malaha, 2020; Ridasta, 2020). Hal ini menunjukkan bahwa informasi tentang kesehatan dan keselamatan kerja menggunakan bahan kimia di laboratorium masih perlu ditingkatkan.

Sebagai upaya untuk mengatasi permasalah minimnya pengetahuan dan pemahaman kesehatan dan keselamatan kerja menggunakan bahan kimia telah dilakukan pengembangan video panduan menggunakan bahan kimia. Melalui video diharapkan dapat melengkapi informasi mengenai pengetahuan kesehatan dan keselamatan menggunakan bahan kimia. Keselamatan kerja di laboratorium harus diinformasikan secara memadai agar mahasiswa (praktikan) betul-betul memahami cara kerja menggunakan bahan kimia dan menyadari bahaya yang ditimbulkan. Hal tersebut perlu dijelaskan berulang-ulang agar kedisiplinannya meningkat dan menjadi kebiasaan. Salah satu media yang dapat membantu penyampaian informasi tersebut adalah media video. Media pembelajaran video merupakan salah satu media sebagai alat bantu dalam proses pembelajaran untuk mencapai tujuan pembelajaran yang optimal. Salah satu fungsi utama media pembelajaran adalah sebagai alat bantu mengajar yang turut mempengaruhi iklim, kondisi, dan lingkungan belajar, yang ditata dan diciptakan oleh guru (A. Arsyad, 2013). Sementara itu, peranan media pembelajaran dalam proses belajar dan mengajar sangat penting dilaksanakan oleh para pendidik saat ini, karena peranan media pembelajaran dapat digunakan untuk menyalurkan pesan pengirim kepada penerima dan melalui media pembelajaran juga dapat membantu peserta didik untuk menjelaskan sesuatu yang disampaikan oleh pendidik (Tafonao, 2018). Hal ini sejalan dengan fungsi media yang juga memberikan pengalaman kongkret pada siswa (Azhar Arsyad, 2014). Kelebihan video di dalam multimedia adalah menjelaskan keadaan riel dari suatu proses; dapat memperkaya penyajian/penjelasan; pengguna dapat melakukan pengulangan (replay); sangat cocok untuk mengajarkan materi dalam ranah psikomotor (seperti praktikum); menunjukkan dengan jelas suatu langkah prosedural, misal cara menuangkan zat kimia (Munir, 2020). Tujuan penelitian ini adalah untuk menganalisis efektivitas pemanfaatan media video panduan kerja menggunakan bahan kimia untuk meningkatkan pengetahuan/pemahaman mahasiswa (praktikan) mengenai kesehatan dan keselamatn kerja di laboratorium kimia. Dalam penelitan ini ingin dilakukan pengujian efektivitas pemanfaatan video panduan menggunakan bahan kimia sebagai media untuk meningkatkan pengetahuan kesehatan dan keselamatan kerja menggunakan bahan kimia.

\section{Metode}

Jenis penelitian ini adalah eksperimen, desain penelitian Pre-Experimental dengan model desain One-Group Pretest- Posttest Design (Sugiyono, 2018). Rancangan penelitian one group pretest-posttest design, terdapat pretest sebelum diberi perlakuan dan posttest men setelah perlakuan (treatmen). Bentuk bagan desain tersebut disajikan pada Gambar 1.

\begin{tabular}{lll}
\hline 01 & $X$ & 02 \\
\hline Pretest & Treatmen & Postest \\
\hline
\end{tabular}

Gambar 1. Bagan One-Group Pretest- Posttest Design (Sugiyono, 2018) 
Penelitian ini dilakukan di Laboratorium Kimia Organik, Jurusan Kimia FMIPA Undiksha dan secara daring. Populasi dalam penelitian ini adalah mahasiswa semester 5 Jurusan Kimia FMIPA Undiksha. Pengambilan sampel dilakukan dengan teknik simple random sampling melalui google form, dipilih 31 orang secara acak dari keseluruhan mahasiswa yang mengisi form. Variabel bebas dalam penelitian ini adalah penggunaan media video untuk menginformasikan cara sehat dan selamat di dalam menggunakan bahan kimia. Sedangkan variabel terikat dalam penelitian ini adalah pengetahuan kesehatan dan keselamatan menggunakan bahan kimia mahasiswa (pretest dan posttest). Instrumen yang digunakan dalam penelitian ini adalah angket dan tes. Angket yang diberikan kepada mahasiswa (responden) berupa angket tertutup dengan model rating scale (skala Likert) skor 1- 4 yang disajikan dalam format google form. Angket dalam penelitian ini dibuat dalam bentuk check list yang diisi oleh mahasiswa dengan jumlah pernyataan 25 butir. Opsi skor dalam angket tersebut adalah 1 untuk jawaban "tidak setuju", 2 untuk jawaban "kurang setuju", 3 untuk jawaban "setuju", dan 4 untuk jawaban "sangat setuju". Tes yang diberikan berupa tes awal dan tes akhir dalam bentuk soal pilihan ganda dengan ketentuan skor 1 untuk jawaban benar dan skor 0 untuk jawaban salah.

Teknik pengambilan data dilakukan dengan memberikan pretes kepada responden sebelum diberikan perlakuan (treatment), dengan tujuan untuk mengetahui pengetahuan awal. Selanjutnya dilakukan pemberian perlakuan (treatment) berupa menyimak video panduan menggunakan bahan kimia kepada responden. Setelah diberikan menyimak video, responden diberi tes akhir (posttes) untuk mengetahui seberapa besar pengaruh pemberian menyimak video terhadap pengetahuan kesehatan dan keselamatan menggunakan bahan kimia. Pengambilan data respons mahasiswa dilakukan dengan memberi angket respon kepada mahasiswa (sampel responden) setelah menyimak video. Uji validitas dan reliabilitas instrument dilakukan dengan bantuan SPSS 25.0. Analisis data dilakukan dengan menggunakan uji Paired Sample $t$ Test dan uji persentase efektivitas. Uji Paired Sample t Test digunakan untuk menguji efektivitas pemberian video panduan menggunakan bahan dengan membandingkan hasil tes awal (pretest) dengan tes akhir (posttes). Sedangkan uji persentase digunakan untuk menghitung persentase capaian skor post tes tehadap skor ideal. Penentuan skor ideal dihitung dari hasil perkalian antara nilai skor jawaban maksimal dikalikan dengan jumlah responden penelitian dan jumlah butir pernyataan dalam angket. Harga persentase yang diperoleh dikonversi menjadi data kualitatif dengan lima kategori, yakni: 1) tidak baik, 2) kurang baik, 3) cukup baik, 4) baik, dan 5) sangat baik. Sebagai persyaratan Uji Paired Sample t Test, terlebih dahulu dilakukan uji normalitas (untuk mengetahui data yang diperoleh berdistribusi normal atau tidak) dan uji homogenitas (untuk mengetahui seragam tidaknya variansi sampel).

\section{Hasil dan pembahasan}

\section{Hasil Penelitian}

Hasil penilaian video oleh mahasiswa dikumpulkan melalui aplikasi gooogle form dengan menyampaian angket respons kepada mahasiswa setelah diberikan menyimak video panduan menggunakan bahan kimia. Sebelum menganalisis hasil penilaian video oleh mahasiswa, dilakukan perhitungan validitas dan reliabelitas instrument (angket) yang dipergunakan. Pengujian validitas butir angket respon mahasiswa terhadap video panduan menggunakan bahan kimia dilakukan dengan uji korelasi bivariat metode product moment Pearson dengan bantuan Program SPSS-25.0. Ketentuan penentuan validitas butir soal (untuk $\mathrm{N}=31$, pada taraf signifikansi $5 \%, \mathrm{r}$ table $=0,355$ ) adalah: jika nilai signifikasi 2-tailed > r tabel, maka "valid", namun jka sig 2-tailed < r tabel, maka "tidak valid". Berdasarkan hasil pengujian korelasi product moment Pearson, diketahui nilai sig (2-tailed) > 0,355. Hasil pengujian tersebut menunjukkan butir angket yang dipakai "valid". Uji reliabilitas angket respon mahasiswa terhadap video panduan menggunakan bahan kimia dilakukan dengan Reliability Statistics Cronbach's Alpha menggunakan bantuan aplikasi SPSS 25. Harga Alpha Cronbach yang diperoleh dikategorikan menurut kriteria normatif Guilford, Berdasarkan tabel hasil uji reliabilitas angket menunjukan nilai Cronbach's Alpha sama dengan $0,934>0.6$, menunjukkan reliabelitas angket terkategori sangat tinggi.

Selanjutkan dilakukan penyampaian angket respons kepada mahasiswa (responden) melalui google form. Jenis angket yang dipergunakan adalah angket tertutup dengan model rating scale antara skor 1-4. Jumlah pernyataan pada angket sebanyak 25 butir, terdiri atas 20 butir pernyataan positif dan 5 butir pernyataan negatif. Angket dalam penelitian ini dibuat dalam bentuk check list yang diisi oleh mahasiswa dengan cara mencentang salah satu opsi sesuai pilihannya. Opsi skor dalam angket tersebut adalah 1 untuk jawaban "tidak setuju", 2 untuk jawaban "kurang setuju", 3 untuk jawaban "setuju", dan 4 untuk jawaban "sangat setuju". Analisis data dilakukan dengan menghitung persentase dari jumlah total skor respons terhadap skor ideal. Penentuan skor ideal dihitung dari hasil perkalian antara nilai skor jawaban maksimal yaitu 4 (empat) dikalikan dengan jumlah responden penelitian dan jumlah butir pernyataan dalam angket. Data hasil respon mahasiswa disusun dalam bentuk tabel skor. Harga persentase yang diperoleh dikonversi 
menjadi data kualitatif dengan lima kategori, yakni: 1) tidak baik, 2) kurang baik, 3) cukup baik, 4) baik, dan 5) sangat baik. Berdasarkan hasil analisis angket respons mahasiswa diperoleh nilai persentase $=91,13 \%$. Hasil persentase tersebut ditunjukkan pada Tabel 1.

Tabel 1. Kategori Respon Mahasiswa terhadap Video Panduan Menggunakan Bahan Kimia

\begin{tabular}{ccccl}
\hline Jumlah Responden & Skor Total & Skor Ideal & Persentase (\%) & Kategori \\
\hline 31 & 2825 & 3100 & $91,13 \%$ & Sangat Baik \\
\hline
\end{tabular}

Uji efektivitas video panduan menggunakan bahan kimia dilakukan dengan perbandingan (komparasi) skor pengetahuan kesehatan dan keselamatan kerja menggunakan bahan kimia sebelum dan sesudah menyimak video panduan menggunakan bahan kimia. Pengumpulan data pengetahuan kesehatan dan keselamatan kerja menggunakan bahan kimia dilakukan dengan memberikan pre tes dan post tes berupa paket soal pilihan ganda sebanyak 23 butir soal dengan ketentuan skor 1 untuk jawaban benar dan skor 0 untuk jawaban salah. Sebelumnya juga dilakukan uji validitas dan reliabilitas butir soal dengan uji korelasi bivariat metode product moment Pearson dengan bantuan Program SPSS-25.0. Ketentuan penentuan validitas butir soal (untuk $\mathrm{N}=31$, pada taraf signifikansi $5 \%, \mathrm{r}$ table $=0,355$ ) adalah: jika nilai signifikasi 2-tailed > r tabel, maka "valid", namun jka sig 2-tailed < r tabel, maka "tidak valid". Berdasarkan hasil pengujian korelasi product moment Pearson (terlampir), diketahui nilai sig (2-tailed) $>0,355$. Hasil pengujian tersebut menunjukkan butir soal tes yang dipakai "valid". Uji reliabilitas dilakukan dengan Reliability Statistics Cronbach's Alpha menggunkan bantuan SPSS 25. Berdasarkan nilai r hasil corrected item total correlation, angket yang dipakai menunjukkan nilai Alpha Cronbach $=0,872>0,6$, menunjukkan tes pengetahuan kesehatan dan keselamatan menggunakan bahan kimia yang dipergunakan memiliki reliabilitas sangat tinggi. Distribusi skor pre tes pengetahuan keshatan dan keselamatan kerja (K3) menggunakan bahan kimia disusun dalam bentuk tabel seperti pada Tabel 2 .

Tabel 2. Distribusi Skor Pre Tes Pengetahuan K3 Menggunakan Bahan Kimia

\begin{tabular}{lccc}
\hline Kategori & Interval & Frekuensi & Persentase \\
\hline Tidak Baik & $25-40$ & 0 & $0 \%$ \\
Kurang Baik & $41-55$ & 5 & $16 \%$ \\
Cukup Baik & $56-70$ & 10 & $32 \%$ \\
Baik & $71-85$ & 13 & $42 \%$ \\
Sangat Baik & $86-100$ & 3 & $10 \%$ \\
\hline Total & & $\mathbf{3 1}$ & $\mathbf{1 0 0 \%}$ \\
\hline Rata-rata & & $\mathbf{6 9 . 8 6}$ \\
\hline
\end{tabular}

Distribusi skor post tes pengetahuan kesehatan dan keselamatan kerja (K3) menggunakan bahan kimia ditunjukkan pada Tabel 3. Pada tabel ditunjukkan skor rata-rata $=81,50$, terkategori baik. Sebaran skor dapat dirinci sebagai berikut: hanya 3\% yang masih berada pada kategori kurang, 23\% kategori cukup, 19\% kategori baik, dan 55\% mencapai kategori sangat baik.

Tabel 3. Distribusi Skor Post Tes pengetahuan K3 Menggunakan bahan Kimia

\begin{tabular}{lccc}
\hline \multicolumn{1}{c}{ Kategori } & Interval & Frekuensi & Persentase \\
\hline Tidak Baik & $25-40$ & 0 & $0 \%$ \\
Kurang Baik & $41-55$ & 1 & $3 \%$ \\
Cukup Baik & $56-70$ & 7 & $23 \%$ \\
Baik & $71-85$ & 6 & $19 \%$ \\
Sangat Baik & $86-100$ & 17 & $55 \%$ \\
\hline Total & & $\mathbf{3 1}$ & $\mathbf{1 0 0 \%}$ \\
\hline Rata-rata & & & $\mathbf{8 1 . 5 0}$ \\
\hline
\end{tabular}

Untuk lebih jelasnya, perbandingan hasil pre tes dan post tes disajikan secara bersama-sama pada Gambar 2. Pada Gambar 2 nampak jelas hasil post tes sebagian besar berada pada kategori baik ke atas (74\%), bahkan terkategori sangat baik mencapai 55\%. Sementara hasil pre tes terkategori sangat baik hanya $3 \%$. Peningkatan yang sangat mencolok terjadi pada kategori sangat baik, dari sbelumnya hanya $10 \%$ menjadi 55\%. Hal ini menunjukkan pemberian video panduan menggunakan bahan kimia dapat meningkatkan pengetahuan kesehatan dan keselamatan kerja. 


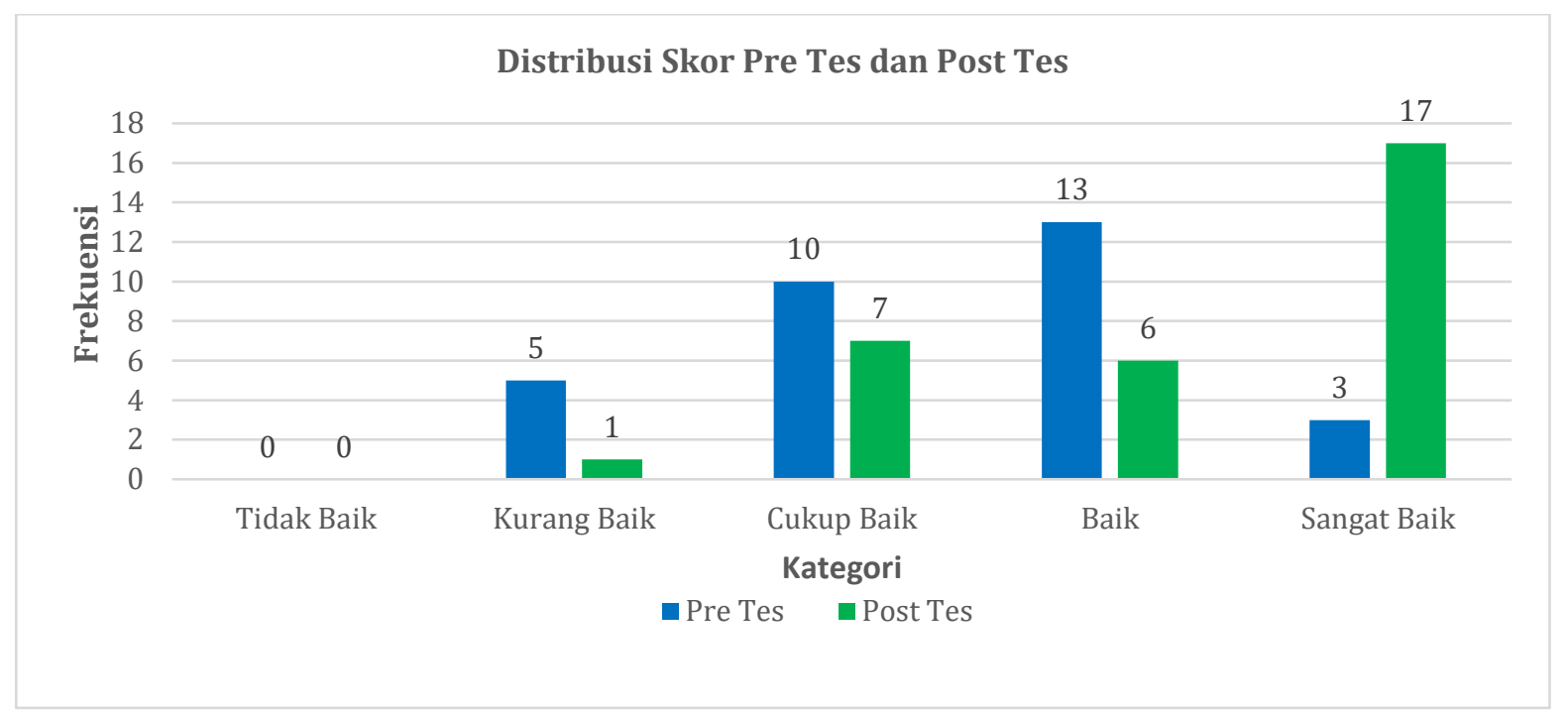

Gambar 2. Grafik Nilai Pre-test dan Post-test Pngetahuan K3 Menggunakan Bahan Kimia

Untuk mengetahui signifikansi perbandingan skor pengetahuan kesehatan dan keselamatan kerja menggunakan bahan kimia sebelum dan sesudah menyimak video panduan menggunakan bahan kimia, dilakukan Uji Paired Sample T tes (uji t) terhadap hasil pre tes dan post tes. Dipergunakan Paired Sample T test karena yang diuji adalah beda dua sampel berpasangan berdasarkan rata-rata. Sampel berpasangan dalam penelitian ini merupakan subjek yang sama namun memiliki perlakuan yang berbeda yakni sebelum dan sesudah diberi menyimak video panduan menggunakan bahan kimia. Sebagai persyaratan Uji Paired sample $t$ tes, terlebih dahulu dilakukan uji normalitas dan uji homogenitas. Uji normalitas menggunakan Tests of Normality Shapiro-Wilk dan uji homogenitas dilakukan Test of Homogeneity of Variances dengan bantuan aplikasi SPSS 25. Hasil uji normalitas ditunjukkan pada Tabel 4.

Tabel 4. Tests of Normality

\begin{tabular}{lccccrr}
\hline & \multicolumn{2}{c}{ Kolmogorov-Smirnov $^{\mathbf{a}}$} & \multicolumn{3}{c}{ Shapiro-Wilk } \\
\cline { 2 - 6 } & Statistic & df & Sig. & Statistic & df & Sig. \\
\hline Pre Tes & .157 & 31 & .050 & .940 & 31 & .082 \\
Post Tes & .160 & 31 & .041 & .940 & 31 & .081 \\
\hline
\end{tabular}

Ketentuan dalam uji normalitas: Jika nilai sig $>0.05$, berarti sampel berdistribusi normal, jika nilai sig $<0,05$, berarti sampel tidak berdistribusi normal. Untuk jumlah sampel kurang dari 50, dipakai nilai Shapiro-Wilk, untuk sampel lebih dari 50 dipakai nilai Kolmogorov-Smirnov. Pada penelitian ini, jumlah sampel adalah 31, maka dipakai nilai signifikanasi Shapiro-Wilk. Berdasarkan tabel Tests of Normality, nilai sig Shapiro-Wilk untuk sampel pre tes $=0.082$ dan nilai sig Shapiro-Wilk sampel post tes $=0.081$. Keduaduanya lebih besar dari 0,05, menunjukkan baik data skor pre tes maupun post tes berdistribusi normal. Berdasarkan hasil pengujian menggunakan Test of Homogeneity of Variances, diperoleh hasil uji homogenitas seperti ditunjukkan pada Tabel 5.

Tabel 5. Test of Homogeneity of Variances

\begin{tabular}{llrrrr}
\hline & & Levene Statistic & df1 & df2 & Sig. \\
\hline Pengetahuan & Based on Mean & .129 & 1 & 60 & .721 \\
Bahan Kimia & Based on Median & .067 & 1 & 60 & .797 \\
& Based on Median and with adjusted df & .067 & 1 & 59.937 & .797 \\
& Based on trimmed mean & .097 & 1 & 60 & .757 \\
\hline
\end{tabular}

Ketentuan dalam uji homogenitas: Jika nilai sig $>0.05$, berarti sampel homogen, jika nilai sig $<0,05$, berarti sampel tidak homogen. Berdasarkan tabel Test of Homogeneity of Variances, nilai signifikansi lebih dari 0,05 , menunjukkan data pre tes dan post tes bersifat homogen. Setelah dilakukan uji normalitas dan 
homogenitas, dilakukan Uji Paired Sample T Tes dengan bantuan aplikasi SPSS 25. Hasil pengujian disajikan pada Tabel 6.

Tabel 6. Hasil Uji Paired Sample T-Test

\begin{tabular}{|c|c|c|c|c|c|c|c|c|c|}
\hline & & \multicolumn{5}{|c|}{ Paired Differences } & \multirow{3}{*}{$\mathrm{t}$} & \multirow{3}{*}{ df } & \multirow{3}{*}{$\begin{array}{l}\text { Sig. } \\
(2- \\
\text { tailed) }\end{array}$} \\
\hline & & \multirow[t]{2}{*}{ Mean } & \multirow[t]{2}{*}{$\begin{array}{c}\text { Std. } \\
\text { Deviation }\end{array}$} & \multirow{2}{*}{$\begin{array}{l}\text { Std. } \\
\text { Error } \\
\text { Mean }\end{array}$} & \multicolumn{2}{|c|}{$\begin{array}{c}\text { 95\% Confidence } \\
\text { Interval of the } \\
\text { Difference } \\
\end{array}$} & & & \\
\hline & & & & & Lower & Upper & & & \\
\hline Pair 1 & $\begin{array}{l}\text { Pre Tes - } \\
\text { Post Tes }\end{array}$ & $\begin{array}{c}- \\
11.64194 \\
\end{array}$ & 6.97040 & 1.25192 & -14.19870 & -9.08517 & -9.299 & 30 & .000 \\
\hline
\end{tabular}

Tabel Paired Samples Test merupakan tabel utama dari output yang menunjukkan hasil uji yang dilakukan. Hal ini dapat diketahui dari nilai signifikansi (2-tailed) pada tabel. Nilai signifikansi (2-tailed) dari data penelitian ini adalah $0.000(\mathrm{p}<0.05)$. Menunjukkan hasil test awal (pre tes) dan test akhir (post tes) mengalami perubahan yang signifikan (berarti). Berdasarkan statistika deskriptif tes awal dan tes akhir terbukti test akhir lebih tinggi, menunjukkan pemberian video panduan menggunakan bahan secara sinifikan dapat meningkatkan pengetahuan kesehatan dan keselamatan kerja menggunakan bahan kimia. Analisis persentase skor tes akhir (post tes) pengetahuan kesehatan dan keselamatan kerja menggunakan bahan kimia disajikan pada Tabel 7.

Tabel 7. Kategori Pengetahuan Kesehatan dan Keselamatan Kerja Menggunakan Bahan Kimia

\begin{tabular}{ccccl}
\hline Jumlah Responden & Skor Total & Skor Ideal & Persentase (\%) & Kategori \\
\hline 31 & 581 & 713 & $81,50 \%$ & Efektif \\
\hline
\end{tabular}

Berdasarkan Tabel 7 di atas dapat diketahui bahwa pemberian video panduan menggunakan bahan kimia efektif untuk meningkatkan pengetahuan kesehatan dan keselamatan kerja menggunakan bahan kimia bagi mahasiswa Jurusan Kimia FMIPA Undiksha.

\section{Pembahasan}

Berdasarkan hasil penelitian yang telah diuraikan di atas, diketahui pemberian video panduan menggunakan bahan kimia efektif untuk meningkatkan pengetahuan kesehatan dan keselamatan kerja menggunakan bahan kimia bagi mahasiswa (praktikan). Secara statistik terdapat perbedaan yang signifikan hasil test awal (pre tes) dan test akhir (post tes), dimana tes akhir lebih tinggi dibanding dengan tes awal. Demikian pula hasil analisis prsentase menunjukkan pemberian video panduan menggunakan bahan kimia efektif untuk meningkatkan pengetahuan kesehatan dan keselamatan kerja menggunakan bahan kimia. Hal ini dapat dijelaskan bahwa video panduan menggunakan bahan kimia dapat membantu mengkomunikasikan pesan-pesan kesehatan dan keselamatan kerja menggunakan bahan kimia yang disampaikan. Seperti dikemukan oleh (Sherin \& Dyer, 2017) bahwa video pembelajaran bertujuan membantu mengkomunikasikan pesan-pesan yang disampaikan dapat lebih memberikan pemahaman kepada penerima pesan. Sejumlah penelitian pengembangan media video pembelajaran yang telah dilakukan juga menunjukkan, bantuan media video dapat mendukung berhasilnya pembelajaran. Bahkan, (Munir, 2020), menyebutkan media video sangat cocok untuk mengajarkan materi dalam ranah psikomotor (seperti praktikum) dapat menunjukkan dengan jelas suatu langkah prosedural (misalnya cara menuangkan zat kimia). Demikian pula (Tegeh et al., 2019), minyimpulkan hasil pnlitiannya bahwa media video sangat efektif digunakan dalam meningkatkan hasil pembelajaran. Hal senada dikemukan oleh (Ariaji et al., 2019) bahwa tambahan bahan ajar berupa video pembelajaran kimia dapat mempengaruhi kemauan belajar, sehingga mendapatkan banyak informasi dalam terlaksananya proses pembelajaran.

Tujuan inti penerapan manajemen K3 di laboratorium adalah memberi perlindungan petugas maupun pengguna laboratorium. Keselamatan kerja di laboratorium harus diinformasikan secara memadai agar mahasiswa (praktikan) betul-betul memahami cara kerja menggunakan bahan kimia dan menyadari bahaya yang ditimbulkan. Hal tersebut perlu dijelaskan berulang-ulang agar kedisiplinannya meningkat dan menjadi kebiasaan. Informasi kesehatan dan keselamatan kerja yang disajikan melalui media video menjadi lebih menarik, mudah diakses lebih awal dimana saja dan dapat diulang-ulang. Hal ini memberi kemudahan bagi mahasiswa (praktikan) untuk mengetahui/memahami serta meningkatkan pengetahuan kesehatan dan keselamatan kerja menggunakan bahan kimia. Video panduan menggunakan bahan kimia untuk kesehatan dan keselamatan kerja di laboratorium yang dikembangkan dalam penelitian ini adalah 
video khusus yang memuat konten cara kerja menggunakan bahan kimia yang sering digunakan di laboratorium kimia organik/biokimia Jurusan Kimia FMIPA Undiksha. Memiliki kesesuaian dengan kondisi riil yang dihadapi oleh pengguna laboratorium kimia tersebut. Oleh karena itu efektif untuk meningkatkan pengetahuan kesehatan dan keselamatan kerja menggunakan bahan kimia di laboratorium kimia FMIPA Undiksha. Video panduan tersebut selanjutnya dapat dipakai sebagi media untuk melengkapi minimnya upaya pemberian penjelasan cara kerja menggunakan bahan kimia sehingga dapat meningkatkan kesehatan dan keselamatan kerja di laboratorium kimia. Media video dapat memberikan penjelasan yang lebih konkret dan menarik secara visual kepada pengguna (mahasiswa). Vidio bisa diputar berulang-ulang sesuai keperluan hingga betul-betul dipahami. Lebih-lebih jika dikaitkan dengan kondisi new normal seperti sekarang ini pemanfaatan media belajar seperti video sangat relevan. Dengan demikian, media video dapat membantu mahasiswa untuk memaksimalkan pengetahuan, meningkatkan pemahaman dan menumbuhkan kesadaran mengenai kesehatan dan keselamatan kerja di laboratorium kimia.

Disarankan bagi praktikan/pengguna laboratorium disarankan agar dapat memanfaatkan video panduan menggunkan bahan kimia sebelum bekerja menggunakan bahan kmia di laboratorium. Bagi pengampu/petugas praktikum sebelum melaksanakan kegiatan praktikum agar memastikan bahwa pengguna laboratorium (praktikan) sudah mempelajari/memahami terlebih dahulu sifat bahan, potensi bahaya bahan yang akan digunakan serta cara penanganannya jika terjadi kecelakaan. Disarankan, dapat menggunakan video panduan tersebut sebagai salah satu rujukan. Bagi peneliti lainnya disarankan untuk pengembangan penelitian misalnya mengenai pengaruh pemanfaatan video panduan menggunakan bahan kimia terhadap kinerja praktikum mahasiswa

\section{Simpulan dan saran}

Video panduan menggunakan bahan kimia terbukti secara signifikan dapat meningkatkan pengetahuan kesehatan dan keselamatan kerja menggunakan bahan kimia. Hasil uji efektifitas menunjukkan, video panduan menggunakan bahan kimia efektif untuk meningkatkan pemahaman kesehatan dan keselamatan kerja menggunakan bahan kimia pada praktikum kimia organik/biokimia bagi mahasiswa Jurusan Kimia FMIPA Undiksha. Video panduan tersebut sebagai salah satu rujukan. Bagi peneliti lainnya disarankan untuk pengembangan penelitian misalnya mengenai pengaruh pemanfaatan video panduan menggunakan bahan kimia terhadap kinerja praktikum mahasiswa.

\section{Ucapan Terimakasih}

Dalam pelaksanaan penelitian ini, penulis telah banyak menerima bantuan moril maupun material dari berbagai pihak. Oleh karenyanya sudah sepatutnya penulis menyampaikan ucapan terima kasih terutama kepada yang terhormat Direktur Sumber Daya Direktorat Jenderal Pendidikan Tinggi Kementerian Pendidikan dan Kebudayaan yang telah memberi bantuan dana penelitian sesuai surat kontrak SPK No. 19/E4.3/KU/2020. Dekan FMIPA Undiksha, Ketua Jurusan dan Ketua Laboratorium Pendidikan Kimia, FMIPA Undiksha yang telah memfasilitasi pelaksanaan penelitian ini. Semua pihak yang tidak disebutkan satu persatu, atas bantuan dan kontribusinya dalam penelitian ini.

\section{Daftar Rujukan}

Ariaji, R., Nasirsah, N., \& Siregar, S. A. (2019). Pengembangan Video Pembelajaran Kimia SMA/MA Menggunakan Camtasia Studio 8. EKSAKTA :JurnalPenelitian Dan Pembelajaran MIPA, 5(1), 47-55. https://doi.org/10.31604/eksakta.v5i1.55-64.

Arsyad, A. (2013). Media Pembelajaran. Rajawali Press.

Arsyad, Azhar. (2014). Media Pembelajaran dalam Pendidikan. Rajawali Press.

Goh, E., \& Lee, C. (2018). A workforce to be reckoned with: The emerging pivotal Generation Z hospitality workforce. International Journal of Hospitality Management, 73(January), 20-28. https://doi.org/10.1016/j.ijhm.2018.01.016.

Imansari, N., \& Sunaryantiningsih, I. (2017). Pengaruh Penggunaan E-Modul Interaktif Terhadap Hasil Belajar Mahasiswa Pada Materi Kesehatan dan Keselamatan Kerja. VOLT : Jurnal Ilmiah Pendidikan Teknik Elektro, 2(1), 11-16. https://doi.org/http://dx.doi.org/10.30870/volt.v2i1.1478.

Isnainy, H., Hasyim, H., \& Sitorus, R. J. (2014). Implementasi Keselamatan dan Kesehatan Kerja di Laboratorium Kimia Fakultas Matematika dan Ilmu Pengetahuan Alam Universitas Sriwijaya Tahun 2009. Jurnal Kesehatan https: //ejournal.fkm.unsri.ac.id/index.php/jikm/article/view/126.

Lasia, I. K. (2013). Analisis Pengetahuan Mahasiswa Tentang Dampak Penggunaan Bahan Kimia Dalam 
Praktikum Kimia Organik terhadap Kesehatan (Studi Menuju Pengelolaan Laboratorium Kimia yang Aman Bagi Kesehatan). Prosiding Seminar Nasional MIPA.

Malaha, A. (2020). Analisis Upaya Pencegahan Kecelakaan Kerja Pada Tenaga Kerja Pada Tenaga Laboran di Sekolah Tinggi Ilmu Kesehatan Bina Mandiri Gorontalo. Journal of Health, Technology and Science (JHTS), 1(1), 1-6. https: //doi.org/10.47918/jhts.v1i1.17.

Munir. (2020). Multimedia Konsep \& Aplikasi Dalam Pendidikan. In Antimicrobial agents and chemotherapy. Antimicrobial agents and chemotherapy.

Purnomo, E. S., \& Saputro, D. E. (2016). Evaluasi Penerapan Prinsip Kesehatan Dan Keselamatan Kerja ( K3 ) Pada Pelaksanaan Kegiatan Praktikum. Integrated Lab Journal, 4(2), 207-216. http://202.0.92.5/pusat/integratedlab/article/view/1135.

Ridasta, B. A. (2020). Penilaian Sistem Manajemen Keselamatan dan Kesehatan Kerja di Laboratorium Kimia. HIGEIA (Journal of Public Health Research and Development), 4(1), 64-75. https://doi.org/10.15294/higeia.v4i1.33891.

Sherin, M. G., \& Dyer, E. B. (2017). Teacher Self-captured Video: Learning to See. Phi Delta Kappan, 98(7), 49-54. https://doi.org/10.1177/0031721717702632.

Subamia, I. D. P., Sriwahyuni, I. G. A. N., \& Widiasih, N. N. (2019). Analisis Resiko Bahan Kimia Berbahaya di Laboratorium Kimia Organik. Wahana Matematika Dan Sains: Jurnal Matematika, Sains, Dan Pembelajarannya, 13(1), https://ejournal.undiksha.ac.id/index.php/JPM/article/download/17144/pdf.

Sugiyono. (2018). Metode Peneiltian Kuantitatif, Kualitatif dan R\&D. In Alfabeta Bandung.

Susiani, I. I. (2017). Program Keselamatan dan Kesehatan Kerja sebagai Wujud dari Kebijakan K3 di PT. Indocement Tunggal Prakarsa, Tbk. Higeia Journal of Public Health Research and Development, 1.

Syakbania, D. N., \& Wahyuningsih, A. S. (2017). Program Keselamatan Dan Kesehatan Kerja Di Laboratorium Kimia. HIGEIA (Journal of Public Health Research and Development), 1(2), 49-57. https://journal.unnes.ac.id/sju/index.php/higeia/article/view/14126.

Tafonao, T. (2018). Peranan Media Pembelajaran dalam Meningkatkan Minat Belajar Mahasiswa. Jurnal Komunikasi Pendidikan, 2(2), 103-114. https://doi.org/10.32585/jkp.v2i2.113.

Tegeh, I. M., Simamora, A. H., \& Dwipayana, K. (2019). Pengembangan Media Video Pembelajaran Dengan Model Pengembangan 4D Pada Mata Pelajaran Agama Hindu. Mimbar Ilmu, 24(2), 158-166. https://doi.org/10.23887/mi.v24i2.21262.

Yamin, M. (2020). Perilaku Keselamatan dan Kesehatan Kerja (K3) Siswa dalam Pembelajaran Praktikum di SMKN 2 Sidenreng. Jurnal of Admiration, 1(3), 207-214. http://jurnalsyntaxadmiration.com/index.php/jurnal/article/view/59. 